\title{
Photochemically triggered alkylthiol reactions on highly ordered pyrolytic graphite
}

Laura Soldi, ${ }^{a}$ Ronan J. Cullen, ${ }^{a}$ Dilushan R. Jayasundara, ${ }^{a}$ Eoin M. Scanlan, ${ }^{a}$ Silvia Giordani ${ }^{a, b}$ and Paula E. Colavita. ${ }^{a,}$

a - School of Chemistry, University of Dublin Trinity College, College Green, Dublin 2, Ireland.

b - Centre for Research on Adaptive Nanostructures and Nanodevices (CRANN), Trinity College Dublin, Dublin 2, Ireland

* Corresponding author. E-mail: colavitp@tcd.ie. 


\begin{abstract}
The surface of highly oriented pyrolitic graphite (HOPG) has been modified using a new photochemically induced grafting reaction. Thiols have been revealed to behave as privileged substrates for this efficient grafting process. The reaction occurs under extremely mild conditions with visible light and at room temperature. The formation of molecular layers on the graphitic surface has been probed by X-Ray Photoelectron Spectroscopy, Cyclic Voltammetry and Infrared Reflectance Absorption Spectroscopy. The reaction was investigated in the presence of thiols bearing different terminal groups $\left.\mathrm{COOH},-\mathrm{OH},-\mathrm{CH}\left(\mathrm{NHCOCH}_{3}\right) \mathrm{COOH},-\mathrm{COOCH}_{2} \mathrm{CH}_{3}\right)$ and in different solvent solutions (DMF, EtOH, $\mathrm{CH}_{3} \mathrm{CN}$ ). Carboxyl and hydroxyl groups as well as the use of acetonitrile as a solvent were found to facilitate the reaction. Our results suggest that the reaction mechanism proceeds via photoinduced electron transfer from the HOPG into the liquid to form highly reactive alkyl radicals able to graft the surface. This type of reactivity of a graphite substrate may be important for general modification strategies of nanotubes and graphene and for new applications of carbon-based materials in photocatalysis.
\end{abstract}

Keywords: photochemical, HOPG, graphite, functionalization, thiols, mercaptans, organothiols, photoinduced. 


\section{Introduction}

Highly graphitic carbons and nanostructured $\mathrm{sp}^{2}$ carbons (e.g. nanotubes, graphene, fibers, graphite powder etc) are of great interest for many current and potential applications, for instance, in the areas of electrochemistry, electronics, sensing, catalysis, supercapacitors, fuel cells and gas storage. Many of these applications rely on interactions that take place at the interface (adsorption, charge transfer, induced dipoles); modulating the interfacial properties of these materials has therefore become of increasing importance. Surface functionalization of these systems has been proposed as a method, for instance, of controlling charge carrier type and concentration, of modulating physical and chemical interactions with molecules, and as an approach to improve handling and processability. ${ }^{1-5}$

Photochemical reactions involving interfacial charge transfer have recently emerged as an important class of reactions for the modification of amorphous carbon materials. ${ }^{6-8}$ Photochemical reactions involving graphite and graphene remain, however, relatively unexplored despite recent examples of photoinduced reactivity that suggest that graphitic systems display rich photochemical reactivity. For instance, Kasemo's group has observed photoreduction of water molecules at graphite/ice interfaces. ${ }^{9,10}$ Modestov et al. ${ }^{11-13}$ demonstrated that graphite displays photoelectrochemical behaviour involving photoinduced charge transfer at the electrode/solution interface. Photochemical modification strategies for graphene or graphite have utilized mostly highly reactive molecules with intrinsic photochemical reactivity in order to achieve grafting (peroxides, ${ }^{14}$ nitrenes, ${ }^{4}$ etc). Examples of photoinduced reactions that leverage light absorption by the graphite substrate, instead, are relatively few. However, recent work shows that such processes are possible: photon absorption by single and multi-layer graphene can lead to electron transfer from graphene to radical initiators such as benzoyl peroxide and ultimately to the functionalization of graphene with phenyl groups. ${ }^{14}$

Here we report a new photochemical method for the covalent functionalization of highly ordered pyrolytic graphite (HOPG) using organothiols under visible illumination. Many biomolecules display native thiol groups or can be easily thiolated; therefore, thiol chemistry offers a versatile route for coupling biologically active compounds to graphite or graphene. Furthermore, organothiols bearing a 
wide range of chemical groups are commercially available because of the rich body of research on selfassembly of thiols on gold and therefore offer a significant practical advantage as functional molecules.

Using a combination of infrared spectroscopy, cyclic voltammetry and X-ray Photoelectron Spectroscopy (XPS) we show that thiol-terminated molecules can be photochemically tethered to HOPG from solution and under mild conditions. Based on our results we propose a reaction mechanism involving photoinduced electron transfer at the graphite/solution interface. Attachment of alkylthiols appears to proceed via an electron transfer step coupled to a desulfurization reaction that generates free alkyl radicals responsible for the grafting.

HOPG has previously been used as a convenient and reproducible substrate for studying fundamental chemistry and charge transfer processes at graphitic carbons in general, ${ }^{15,16}$ and is considered a reasonable model for investigating the chemistry of graphene ${ }^{3}$ and nanotubes. ${ }^{17}$ We therefore believe that these results are of general interest in order to improve our understanding of graphene and nanotube photochemistry in general, and to possibly develop new photoswitchable reduction agents based on carbon materials.

\section{Experimental Section}

\section{Chemicals and Materials}

Dimethylformamide (Aldrich, HPLC grade), absolute ethanol (Sigma) and dichloromethane (Fisher, HPLC grade) and acetonitrile (Fisher) were used without further purification; water used for our experiments was deionized. Potassium ferricyanide (Aldrich), potassium chloride (Aldrich) were used without further purification. The following compounds were used as received for surface modification: 11-mercaptoundecanoic acid (MUA, Aldrich), 9-mercapto-1-nonanol 96\% (MNN, Aldrich), N-acetyl-Lcysteine (AcCy, Fluka). Ethyl 11-mercaptoundecanoate (EMU) was synthesized via Fisher esterification from the corresponding acid and ethanol. ${ }^{18,19}$ Highly ordered Pyrolytic graphite (HOPG) wafers were of ZYB grade (NT-MDT) and were surface cleaved immediately prior to experiments using the adhesive tape method. 


\section{HOPG functionalization}

Standard functionalisation reactions were carried out by immersing HOPG wafers in degassed DMF solutions containing $5 \mathrm{mM}$ alkylthiol and $5 \mathrm{mM}$ deionized water. HOPG samples were then irradiated under Ar atmosphere using a commercial compact fluorescent bulb (Solus) for $15 \mathrm{~min}$. The total power incident on the sample was $5.8 \mathrm{~mW}$ as measured using a calorimeter (Model 365, Scientech). The spectral power distribution of the lamp displays three main emission lines at 435, 548 and $615 \mathrm{~nm}$ and a small contribution at $364 \mathrm{~nm}$ (see Supporting Information). After reaction the samples were washed once in DMF and twice in $\mathrm{CH}_{2} \mathrm{Cl}_{2}$ and dried under a stream of nitrogen gas.

\section{Characterization}

Samples were characterized via Infrared reflection-absorption spectroscopy (IRRAS). Spectra were collected on an FTIR spectrometer (Bruker Tensor 27) using a Mercury-Cadmium-Telluride (MCT) detector and a VeeMaxII variable angle specular reflectance accessory with wire grid polarizer. 256 scans at $4 \mathrm{~cm}^{-1}$ resolution were collected for both background and sample using p-polarized light at $70^{\circ}$ incidence from the surface normal. ${ }^{20}$ Except when noted, background samples consisted of HOPG wafers that had undergone exactly the same protocol except for exposure to light. All spectra reported in this work are baseline corrected; typical RMS and peak-to-peak noise levels were always below $2 \times 10^{-5}$ and $1 \times 10^{-4}$ absorbance units respectively.

XPS characterization was performed on an ultra-high vacuum system at $1 \times 10^{-10}$ mbar base pressure (Omicron), equipped with a monochromatized $\mathrm{Al} \mathrm{K}_{\alpha}$ source $(1486.6 \mathrm{eV})$ and a multichannel array detector. Spectra were recorded with an analyzer resolution of $0.5 \mathrm{eV}$ at a $45^{\circ}$ take-off angle. Atomic area ratios were determined by fitting to Gaussian functions after Shirley background correction (Igor Pro $),{ }^{21,22}$ and normalizing the peak area ratios by the corresponding atomic sensitivity factors $(\mathrm{C}=$ $0.296 ; \mathrm{O}=0.711)$.

Cyclic voltammetry was performed using a three-electrode setup using $\mathrm{Pt}$ wire and $\mathrm{Ag} / \mathrm{AgCl}$ (IJ Cambria) as counter and reference electrodes, respectively, on a CHI660C potentiostat. A home-built Teflon cell was used, in which a Viton o-ring pressed against the HOPG working electrode defined an 
electrode area of $0.053 \mathrm{~cm}^{2}$, as determined via Randles-Sevcik plots. ${ }^{23}$ Measurements were performed at room temperature in $\mathrm{Ar}$ purged solutions of $0.001 \mathrm{M} \mathrm{K}_{3} \mathrm{Fe}(\mathrm{CN})_{6}$ using $\mathrm{KCl} 0.1 \mathrm{M}$ as supporting electrolytes.

\section{Results}

\subsection{HOPG reactions with organothiols}

Freshly cleaved HOPG wafers were irradiated for only 15 min in DMF solutions containing both thiols and water in $5 \mathrm{mM}$ concentration. Scheme 1 shows the organothiols used in our experiments: Nacetyl-L-cysteine (AcCy), 11-mercaptoundecanoic acid (MUA), ethyl 11-mercaptoundecanoate (EMU), 9-mercapto-1-nonanol (MNN). In order to investigate the reactivity of HOPG layers with organothiols under irradiation we carried out IRRAS characterization on the HOPG surfaces.

Figure 1 shows IRRAS spectra of the organic layers obtained after photochemical grafting for 15 min on HOPG. All samples display a prominent peak at $1590 \mathrm{~cm}^{-1}$ that is assigned to the infrared active $\mathrm{E}_{1 \mathrm{u}}$ mode of graphite. ${ }^{20}$ Spectra collected after reaction with thiols that possess long alkyl chains show two maxima at $2926 \mathrm{~cm}^{-1}$ and $2852 \mathrm{~cm}^{-1}$ that can be assigned to the asymmetric and symmetric $\mathrm{C}-\mathrm{H}$ stretching modes, respectively, of $\mathrm{CH}_{2}$ groups in the alkyl chains. ${ }^{24-28} \mathrm{~A}$ third peak is clearly visible at $1472 \mathrm{~cm}^{-1}$ and it can be assigned to the bending motion of methylene groups. ${ }^{24-28}$ Because of the presence of only one methylene unit in the AcCy chain, stretching and bending peaks are absent in the AcCy spectrum.

Reactions with MUA and AcCy also yield peaks at 1741 and $1739 \mathrm{~cm}^{-1}$, respectively, that we assign to the $\mathrm{C}=\mathrm{O}$ stretching mode of carboxylic acid groups. AcCy should also display an amide I peak at $\sim 1640 \mathrm{~cm}^{-1},{ }^{29}$ however, spectral features in the region $1550-1650 \mathrm{~cm}^{-1}$ are difficult to detect because of the intense $\mathrm{E}_{1 \mathrm{u}}$ band and the presence of residual water vapor peaks. The position of the $\mathrm{C}=\mathrm{O}$ stretching peak strongly suggests that $-\mathrm{COOH}$ groups are not involved in hydrogen bonding as indicated by previous infrared studies on $\mathrm{MUA}^{27,30,31}$ and $\mathrm{AcCy}^{29}$ monolayers. 
In the case of EMU, which possesses an ester carbonyl moiety, no carbonyl stretching peaks were observed. Control experiments carried out under the same conditions but without irradiation (see Supporting Information) indicate that the alkyl chain modes appear only after irradiation and are indeed the result of EMU grafting to the HOPG surface. The simultaneous presence of $\mathrm{C}-\mathrm{H}$ stretching and absence of $\mathrm{C}=\mathrm{O}$ stretching modes suggests that EMU displays different orientation and/or coverage after reaction with graphite surfaces when compared to MUA or AcCy. ${ }^{20,32}$

HOPG wafers were characterized after reaction using cyclic voltammetry $(\mathrm{CV})$ in the presence of redox couples in solution. Figure 2 shows the cyclic voltammetric response of HOPG electrodes in 0.1 $\mathrm{M} \mathrm{KCl}$ electrolyte containing $0.001 \mathrm{M} \mathrm{K}_{3} \mathrm{Fe}(\mathrm{CN})_{6}$ at $0.075 \mathrm{~V} / \mathrm{s}$ after cleavage (trace A), after reaction with MUA (trace B) and after exposure of HOPG to MUA solutions without irradiation (dark control, trace $\mathrm{C}$ ). The $\mathrm{CV}$ of bare $\mathrm{HOPG}$ electrodes shows oxidation and reduction waves characteristic of $\mathrm{Fe}(\mathrm{CN})_{6}^{3-/ 4-}$ with peak-to-peak separation $\Delta \mathrm{E}_{p}=138 \pm 48 \mathrm{mV}$ ( $s_{\Delta E p}$ calculated from 5 samples $) . \Delta \mathrm{E}_{\mathrm{p}}$ values for $\mathrm{Fe}(\mathrm{CN})_{6}^{3-/ 4-}$ are much larger for near-perfect basal plane graphite (BPG) electrodes (at least $700 \mathrm{mV}$ ), whereas at edge plane graphite (EPG) electrodes the much higher charge transfer results in reversible behaviour $\left(\Delta \mathrm{E}_{\mathrm{p}} \sim 59 \mathrm{mV}\right) .{ }^{33,34}$ Our results therefore indicate that after the cleaving process there is a sufficiently high edge plane coverage (EP) at the surface so that $\Delta \mathrm{E}_{\mathrm{p}}$ values are closer to $\mathrm{EP}$ behaviour. The high sample standard deviation observed $s_{\triangle E p}$ is also a characteristic of HOPG electrodes since even small variations in EP coverage can drastically affect the electrochemical response. ${ }^{35,36}$

After reaction with MUA the voltammetric peaks are entirely suppressed (Figure 2, trace B). This indicates that after reaction with MUA charge-transfer is hindered at the surface, as it typically occurs after the deposition/growth of a blocking layer on the working electrode. This type of voltammetric behaviour has been previously observed in the case of self-assembled monolayers (SAMs) on Au and is an indication of effective passivation and organic layer deposition. ${ }^{25,37,38}$ After reaction with MUA we also observe a decrease in the capacitive contribution to the current as is expected of an insulating layer of finite thickness. ${ }^{25,37,39}$ Similar results were obtained for AcCy and MNN as shown in the Supporting Information. 
Figure 2 also shows a CV obtained under the same conditions when HOPG surfaces are exposed to the MUA solutions but not irradiated (trace C). Reduction and oxidation peaks are clearly visible in the $\mathrm{CV}$ of the dark control, and peak-to-peak separation is $\Delta \mathrm{E}_{p}=320 \mathrm{mV}$. This value is intermediate between those of freshly cleaved and reacted graphite, suggesting that partial adsorption of the molecules takes place at the HOPG-solution interface. ${ }^{32}$ However, only irradiation under reaction conditions leads to complete suppression of the voltammetric peaks indicating that this process induces a profound change at the HOPG surface.

Since IRRAS results indicate that there are differences in the organic layer obtained from EMU and MUA we investigated the electrochemical response of HOPG electrodes after reaction with EMU. Figure 2 shows a CV obtained for HOPG electrodes after reaction with EMU (trace D). Voltammetric peaks of the EMU-HOPG sample are not suppressed, however they are stretched by comparison with a bare HOPG sample. These results indicate that EMU reaction leads to layers of inferior passivating behaviour when compared to MUA-HOPG samples, possibly due to a lower coverage of EMU at the HOPG surface.

In summary, IRRAS results are consistent with the presence of alkyl chains bearing the corresponding organothiol terminal groups after a photochemical reaction on HOPG surfaces. Reaction yield appears to depend on the type of terminal group present on the thiol, whereby thiols with terminal carboxyl and hydroxyl groups yield a higher coverage than ester terminated ones. Similar conclusions were reached via electrochemical characterization methods. Cyclic voltammetry using $\mathrm{Fe}(\mathrm{CN})_{6}^{3-/ 4-}$ in solution show that, after reaction with most of the organothiols, a blocking layer is formed on the graphite surface consistent with surface grafting of organothiols after irradiation. Also in this case, reactivity appears to depend on the surface terminal groups, with carboxy and hydroxyl terminated thiols yielding better passivating layers and consistent with a higher molecular coverage. 


\subsection{Structure and coverage of MUA layers}

In order to obtain quantitative information about the organic layer coverage and to understand structure and composition of the organic layers, we carried out XPS measurements. Figure 3a shows the C1s region of graphite samples after cleaving in air (trace A), after irradiation in DMF solution (trace B), and after irradiation in MUA solutions (trace C). XPS spectra are dominated by the main C1s line of graphite with a maximum at $284.2 \mathrm{eV} .{ }^{40}$ Freshly cleaved graphite shows its characteristic asymmetry at high binding energies ${ }^{41,42}$ and a $\pi-\pi^{*}$ satellite peak at $290.8 \mathrm{eV} \cdot{ }^{40}$ After irradiation in DMF under inert atmosphere the $\mathrm{C} 1 \mathrm{~s}$ spectrum remains unchanged and shows no evidence for the formation of oxygen containing groups in the absence of organothiols. However, when MUA is present in solution the C1s signature develops a well-resolved peak at $288.9 \mathrm{eV}$ that is consistent with the appearance on the surface of $\mathrm{C}=\mathrm{O}$ groups associated to carboxylic acid moieties. ${ }^{31}$

The main peak at $284.2 \mathrm{eV}$ can be attributed mostly to contributions from the graphite substrate, therefore, the area ratio of the peak at $288.9 \mathrm{eV}$ to the main line can be used to estimate the surface coverage of $\mathrm{C}=\mathrm{O}$ groups after reaction. ${ }^{7} \mathrm{~A}$ fit of the spectrum yielded an area ratio $A_{288.9} / A_{284.2}=0.011$; considering an inelastic mean-free path for electrons on graphite $\left(\right.$ density $\left.=2.25 \mathrm{~g} / \mathrm{cm}^{3}\right)$ of $1.896 \mathrm{~nm}^{43}$ and a take-off angle of $45^{\circ}$ we can estimate that the surface coverage is $\sim 5 \times 10^{14}$ molecules $/ \mathrm{cm}^{2}$. This value is similar to that obtained for densely packed organothiol layers on gold and suggests a high reaction yield for photochemical reactions of MUA on $\mathrm{HOPG}^{26}$

Surprisingly, it was not possible to detect any sulfur using XPS. The S2p region for the same sample shown in trace $\mathrm{C}$ is reported in the Supporting Information. The presence of thiols, thiolates or disulfides in this region is characterized by a doublet in the region $162-164 \mathrm{eV},{ }^{26,30,44,45}$ whereas oxidized thiol groups should yield peaks around $168 \mathrm{eV} .{ }^{46}$ The absence of any peaks strongly suggests that thiol groups initially present on the molecule are lost after photochemical reaction with HOPG surfaces. Similar results were obtained after reaction with hydroxyl terminated thiols (see Supporting Information). 


\subsection{Importance of thiol groups and water content}

Since XPS results show no evidence of sulfur-containing groups on the surface after reaction, we investigated whether thiol groups were necessary for the reaction to take place. Figure 4 shows a typical $\mathrm{Fe}(\mathrm{CN})_{6}^{3-/ 4-}$ cyclic voltammogram obtained on freshly cleaved HOPG (trace A), compared to that of HOPG after irradiation in $5 \mathrm{mM}$ solutions of water and undecanoic acid (UA, trace B), the non-thiolated analogue of MUA. Reduction and oxidation peaks are clearly visible and their $\Delta \mathrm{E}_{\mathrm{p}}$ is only marginally different from that of a bare HOPG sample. This behaviour is in clear contrast to that observed after reaction with MUA (Figure 2, trace B) and is compatible with modest physisorption of UA on HOPG surfaces. ${ }^{32}$ The inset shows the $\mathrm{C}=\mathrm{O}$ stretching region of the IRRAS spectrum of UA-HOPG samples showing a lack of absorption bands. These results, therefore, strongly indicate that the presence of sulfhydryl groups is essential for obtaining high coverage layers on graphite surfaces under irradiation and that thiols must behave as privileged substrates in these reactions. The implications of these results together with the lack of S2p peaks in XPS spectra will be examined in the Discussion section.

The effect that water has on the reaction was investigated by carrying out reactions in DMF with different amounts of water in solution. Figure 5a shows IRRAS spectra in the $\mathrm{C}=\mathrm{O}$ stretching region of HOPG samples after reaction with MUA for 15 min in DMF solutions that contained different amounts of water: using anhydrous DMF (trace A), using HPLC grade DMF which is known to contain residual water (trace B), and after water addition to a concentration of $0.005 \mathrm{M}$ (trace C). After reaction with anhydrous $\mathrm{DMF}$, no $\mathrm{C}=\mathrm{O}$ stretching peaks are visible; however, as the amount of water is increased in solution, we observed the development of a $\mathrm{C}=\mathrm{O}$ stretching peak at $1740 \mathrm{~cm}^{-1}$. These spectra indicate that the presence of water facilitates the reaction and, within the timescale of our experiments, appears to be necessary for grafting to take place.

Best results were obtained for $1: 1$ water:thiol ratios and 15 min irradiation time. Longer irradiation times did not improve reaction yields and, on the contrary, were found to lead to organic layer degradation. Figure 5b shows IRRAS spectra of HOPG after reaction in $1: 1$ water:MUA solutions, after $15 \mathrm{~min}$ (trace A) and $3 \mathrm{~h}$ (trace $\mathrm{B}$ ) of irradiation. The absorption peaks associated with $\mathrm{C}=\mathrm{O}$ 
stretching peaks are greatly reduced after long exposure to light in the reaction solution, indicating that, after rapid initial grafting, the reaction self-terminates and any further reactivity leads to degradation of the organic layer at the HOPG-liquid interface.

\subsection{Thermally initiated reactions of thiols on graphite}

Our results indicate that thiol groups are important in order for the reaction to take place. Thiols are known to add to unsaturated systems via thiyl radical formation. We therefore investigated whether the formation of thiyl radicals could be the initial step in the reaction of MUA with HOPG. In order to test this hypothesis we prepared 1:1 solutions of 4,4'-Azobis(4-cyanovaleric acid) (ACVA) and MUA in DMF. ACVA is a radical initiator that can be activated thermally at $75^{\circ} \mathrm{C}^{47,48}$ leading to the formation of thiyl radicals in the presence of thiols in solution. ${ }^{49,50}$ Freshly cleaved HOPG samples were immersed in these solutions under an argon atmosphere and kept at $75^{\circ} \mathrm{C}$ for $1 \mathrm{~h}$ prior to rinsing and characterization. Figure 6 shows a typical IRRAS spectrum of graphite surfaces after these reactions (trace B) compared to the result obtained after photochemical reactions using water (trace A). For the thermally initiated reactions the intensity of both $\mathrm{C}-\mathrm{H}$ and $\mathrm{C}=\mathrm{O}$ stretching peaks is at the limit of detection of our IRRAS measurements, and greatly inferior to that of photochemically initiated reactions. Therefore, formation of thiyl radicals in solution does not appear to lead to effective grafting at the HOPG surface; hence, a different species must be responsible for initiating organothiol reactions on graphite. Furthermore, thiyl addition to electron rich groups leads to the formation of $\mathrm{C}-\mathrm{S}$ bonds that would contribute to XPS peaks in the S2p region. ${ }^{51}$ The absence of S2p peaks after photochemical initiation (Figure 3b) is therefore consistent with a reaction that does not proceed through thiyl radical addition and is also consistent with the observed negligible reaction yields via thiyl radical thermal initiation.

\subsection{EMU reactivity in different solvents}

The EMU reactivity was found to be different in comparison with the corresponding carboxylic acid 
MUA in DMF solution under 15 minutes of irradiation (Figure 2, respectively trace D and B). Therefore its reactivity was investigated in different solvents. Alcohols and $\mathrm{CH}_{3} \mathrm{CN}$ are better than DMF at stabilizing both solvated electrons and anions, ${ }^{52}$ therefore, we decided to investigate the effect of using EtOH or $\mathrm{CH}_{3} \mathrm{CN}$ as reaction solvents on the EMU grafting yield.

Figure 7 shows CVs obtained for HOPG electrodes after reaction with EMU and water (both $5 \mathrm{mM}$ ) carried out in DMF (trace B), EtOH (trace $\mathrm{C}$ ) and $\mathrm{CH}_{3} \mathrm{CN}$ (trace $\mathrm{D}$ ); the $\mathrm{CV}$ for bare HOPG (trace $\mathrm{A}$ ) is also reported for comparison purposes. Under the same conditions the voltammetric peaks of the EMUHOPG samples are significantly suppressed after reactions in $\mathrm{EtOH}$ and $\mathrm{CH}_{3} \mathrm{CN}$ compared to those in DMF. Our results therefore indicate that EMU reactions in $\mathrm{CH}_{3} \mathrm{CN}$ or $\mathrm{EtOH}$ yield layers of higher passivating behaviour in comparison with EMU reaction in DMF (Figure 1, EMU), which is consistent with higher final EMU coverage at the HOPG surface after photochemical reaction.

\section{Discussion}

Our results show that after a photochemical reaction, organothiols bearing different terminal groups were grafted to HOPG surfaces. This reaction is promoted by low energy photons $(\lambda>364 \mathrm{~nm})$ and occurs in the presence of thiols and water in the reaction medium. Thiols are essential for the reaction to take place, however, no sulfur containing groups could be found at the surface after reaction. Although the presence of a thiol group is necessary, not all organothiols graft with the same yield at the HOPG surface since $-\mathrm{COOH}$ and $-\mathrm{OH}$ groups were found to facilitate the reaction compared to $-\mathrm{COOR}$ moieties.

There are few examples of organothiol attachment to carbon surfaces. A first category of reactions relies on the nucleophilic character of the thiol group but it usually requires prior modification of the carbon surface in order to create electrophilic carbon centers. Following this approach Lockett et al. have shown that organothiols in solution can add to $\mathrm{sp}^{2}$-rich amorphous carbon surfaces that had been previously halogenated ${ }^{51}$ or modified with acyl chlorides, ${ }^{53}$ leading to the formation of $\mathrm{S}-\mathrm{C}$ bonds. Alam et al. ${ }^{54}$ carried out the photochemical attachment of thiols to $\mathrm{C}_{60}$, yielding fullerene-thiol adducts 
via reaction of fullerene radicals with thiyl radicals through the formation of $\mathrm{S}-\mathrm{C}$ bonds. It is therefore surprising that in our case we were not able to detect the presence of $\mathrm{S}-\mathrm{C}$ bonds at the surface; thus suggesting that the reaction pathway is fundamentally different from previous thiol-on-carbon reactions and that it must involve cleavage of the $\mathrm{C}-\mathrm{S}$ bond in organothiols.

\section{The importance of light.}

A first important finding is that light in the visible range can be used for this reaction. Neither the solvent nor the organothiols used for these reactions absorb light in the emission range of the light source $\left(\lambda>364 \mathrm{~nm} ; \mathrm{E}_{\mathrm{ph}}<3.3 \mathrm{eV}\right)$ (see Supporting Information). Direct photolysis of organothiols via either $\mathrm{S}-\mathrm{H}$ or $\mathrm{C}-\mathrm{S}$ bonds, in fact, requires much shorter wavelengths typically below $300 \mathrm{~nm},{ }^{55,56}$ and higher photon energies are needed for $\mathrm{C}-\mathrm{S}$ vs. S-H dissociation. ${ }^{56}$ Furthermore, if direct photolysis of the thiol group were sufficient for grafting to occur, we would expect all organothiols to react with similar yields, contrary to our observations. Hence, we conclude that direct photolysis can be excluded as a reaction pathway for HOPG functionalization.

Light absorption by the HOPG substrate must therefore play an important role in these surface reactions. HOPG is a semimetal and optical absorption can lead to the formation of photogenerated charge carriers over a wide range of wavelengths. ${ }^{57-59}$ It has been shown that hot carriers in graphite can transfer to acceptor species in solution ${ }^{11-13}$ or to solvent traps in thin ice films, ${ }^{10}$ leading to redox reactions and physical transformations at the graphite interface, respectively. It is therefore important to consider photoinduced charge transfer as a possible reaction pathway for the surface modifications observed in our experiments.

Based on the optical properties of the liquid phase and of HOPG, we hypothesize that charge transfer is one of the key steps leading to organothiol grafting on HOPG. This idea is also supported by our results that show that protic groups facilitate the reaction, particularly when comparing MUA to its ester analogue EMU. Similar differences in reactivity between analogue ester and acid compounds have been previously observed in photochemical carbon functionalization reactions using terminal alkenes. Terminal alkene reactions are initiated via electron photoemission from the carbon into the liquid phase 
and grafting yields can be enhanced by lowering the photoemission threshold using electron acceptors at the carbon interface. ${ }^{6,60,61}$ Lockett and Smith $^{61}$ showed that $-\mathrm{COOH}$ terminated alkenes indeed displayed grafting yields on amorphous carbons up to ten times higher than those of -COOMe analogues.

Protons are routinely used as electron acceptors in solution and lead to cathodic photocurrent enhancements in photoelectrochemical cells ${ }^{62,63}$ via reaction (1): ${ }^{64,65}$

$$
\mathrm{H}^{+}+\mathrm{e}^{-} \rightarrow \mathrm{H} \bullet
$$

$\mathrm{H}^{+}$facilitates photoelectron emission into liquids both because its acceptor level lowers the threshold to photoemission and because reaction (1) prevents charge recombination. ${ }^{63,66}$ The enhancement of photocurrents thanks to the presence of $\mathrm{H}^{+}$in solution has been experimentally observed in the specific case of HOPG electrodes by Modestov et al. showed that cathodic photocurrents at photon energies of $2.7 \mathrm{eV}$ or lower could be observed in acidified aqueous solutions. ${ }^{11}$

Reaction (1) leads to the formation of hydrogen atoms which can rapidly react further with organic or water molecules. ${ }^{64}-\mathrm{COOH}$ groups display similar reactivity with electrons in the condensed phase because (a) they dissociate protons that react with $\mathrm{e}^{-}$in polar environments according to (1); and (b) when protonated, as expected in DMF media, ${ }^{67}$ they react with electrons to form carboxylate anions and hydrogen atoms. ${ }^{68-72}$-COOR groups can also capture electrons in condensed phases, however, they dissociate mainly into carboxylate anions and alkyl radicals $\mathrm{R}$, which display a completely different chemistry compared to $\mathrm{H} \bullet($ vide infra).

\section{The role of sulfhydryl groups.}

The enhanced reactivity of protic terminal groups supports the argument that photoinduced electron transfer from HOPG into the liquid phase could be a key step in the functionalization process. However, this step alone cannot account for the overall reactivity, since our experiments with alkanoic acids devoid of thiol groups did not lead to surface grafting under similar conditions. The absence of any sulphur in the grafted layers suggests that sulfhydryls act as sacrificial groups in these reactions; a desulfurization step must take place under reaction conditions and this step is probably essential in order to tether the alkyl chains to the HOPG surface. 
Sulfhydryl groups have a rich radical chemistry that accounts for their role in enzyme catalysis and radiation damage. ${ }^{73,74}$ To a large extent their radical chemistry is based on formation of thiyl radicals via hydrogen abstraction. ${ }^{75}$ However, our experiments with thermally generated thiyl radicals clearly show that this species does not lead to effective grafting at HOPG surfaces. Hence we exclude the possibility that the high coverage layers observed with MUA are the result of thiyl radical addition to the graphite surface. On the other hand, it has been demonstrated that RSH molecules undergo $\mathrm{R}-\mathrm{SH}$ cleavage leading to the formation of alkyl radicals under reductive attack by either solvated electrons ${ }^{76,77}$ or hydrogen atoms ${ }^{78-80}$ according to the following reactions:

$$
\begin{aligned}
& \mathrm{H} \bullet+\mathrm{RSH} \rightarrow \mathrm{R} \bullet+\mathrm{H}_{2} \mathrm{~S} \\
& \mathrm{e}^{-}+\mathrm{RSH} \rightarrow \mathrm{R} \bullet+\mathrm{HS}^{-}
\end{aligned}
$$

Reactions (2) and (3) suggest that photoinduced electron transfer into the liquid is a viable route for the generation of highly reactive alkyl radicals in solution. Alkyl radicals are strong alkylating agents and have been shown to be effective agents for the functionalization of graphite and nanotubes; ${ }^{81-84}$ generation of alkyl radicals close to the HOPG/solution interface is therefore very likely to lead to $\mathrm{C}-\mathrm{C}$ covalent anchoring of alkyl fragments. Interestingly, a similar route to that shown in reaction (3) has been proposed for the side-wall alkylation of nanotubes using dodecylsulfides using $\mathrm{Li} / \mathrm{NH}_{3}{ }^{85}$

A proposed mechanism for the reaction of organothiols on HOPG is illustrated in Figure 8, where both protons and solvent traps are shown to facilitate photoemission of electrons from HOPG into the liquid. It is important to notice that in our proposed mechanism, unless photoemission is suppressed after the first layer, radicals are generated continuously and can lead to multilayer grafting together with loss of any unsaturated groups present on the grafted molecules. This phenomenon has been previously observed for photoinduced radical fragmentation at amorphous carbon surfaces ${ }^{6,60}$ and is in agreement with the loss of $\mathrm{C}=\mathrm{O}$ stretching peaks in MUA layers observed after prolonged irradiation (see Figure $5 b)$. Finally, the role of water in this mechanism remains unclear; however, it is possible that it functions as a hole scavenger in order to preserve charge neutrality. ${ }^{86,87}$ 


\section{Improving the yield of ester terminated thiols.}

In the case of $-\mathrm{COOCH}_{3}$ terminated organothiols, based on ESR studies, electron capture leads to the formation of carboxylate anions and ${ }^{\circ} \mathrm{CH}_{3}$ radicals. ${ }^{88}$ These radicals could either react with the HOPG surface directly leading to short alkyl chains tethered to HOPG, or decay via hydrogen abstraction from RSH molecules according to the well known "repair" mechanism of sulfhydryls ${ }^{89}$ (rate constant $k \sim 10^{8}$ $\left.\mathrm{M}^{-1} \mathrm{~s}^{-1}\right) .{ }^{90}$ Either one of these processes would lead to poor passivation of HOPG electrodes both because of grafting of a thin organic layer, or because of no radical addition at the surface in the first place, in agreement with our cyclic voltammetry experiments (Figure 7, trace B).

According to our proposed mechanism, in order to improve the reactivity of $-\mathrm{COOCH}_{3}$ terminated organothiols it is necessary to promote reactions (2) and (3). Reaction (2) would require the addition of an acid, which we decided to avoid in order to exclude the possibility of ester hydrolysis. We then decided to leverage reaction (3) by improving the yield of photoinduced charge transfer processes.

Acetonitrile and ethanol are known to be better solvents than DMF for stabilizing both solvated electrons and anion species. ${ }^{52,91}$ The stabilization of solvated electrons correlates positively with the $\lambda_{\max }$ of bound-bound optical transitions, ${ }^{92-94}$ which for solvated electrons in DMF, acetonitrile and ethanol are reported at $1680 \mathrm{~nm},{ }^{95} 1450 \mathrm{~nm}^{96,97}$ and $680 \mathrm{~nm}^{98}$ respectively. The shorter the $\lambda_{\max }$ the greater the stabilization and, consequently, the lower the expected threshold energy needed to generate solvated electrons at the HOPG/liquid interface. The ability of the solvent to better stabilize anions could also promote reaction (3) by improving the stability of reaction products. In fact, a change in solvent from DMF to acetonitrile is known to frequently lead to positive shifts in electrochemical reduction potentials. ${ }^{99,100}$

These properties have been empirically incorporated into the solvent acceptor number (AN) which for DMF, $\mathrm{CH}_{3} \mathrm{CN}$ and $\mathrm{EtOH}$ is reported at 16.0, 18.9 and 37.9, respectively. ${ }^{91}$ EMU grafting yields in acetonitrile and ethanol follow indeed the trend in solvent acceptor number and support the idea that alkylthiol photochemical grafting to HOPG proceeds via photoinduced electron transfer into the liquid. 


\section{Conclusions}

The generation of alkyl radicals for the purpose of functionalizing graphitic layers has typically relied on the use of precursors with high reactivity and as such unstable or difficult to handle. We have developed a method for the functionalization of graphite based on organothiols and mild irradiation using a common fluorescence bulb, that can lead to the formation of organic layers with high coverage. The use of organothiols is advantageous, from the practical standpoint, because they are stable, easy to handle and, finally, readily available from commercial sources with a wide range of terminal groups. Furthermore, many biomolecules display thiol groups either in their native structure or via standard thiolation protocols; hence, this reaction route opens the possibility of direct biomolecule tethering to graphitic surfaces.

Our experiments provide support for a mechanism of this reaction involving photoinduced reduction of organothiols in solution leading to the formation of highly reactive alkyl radicals in the proximity of the HOPG surface. Based on this mechanistic hypothesis we provide an optimization criterion based on the ability of different solvents to promote electron trapping in solvent cavities. Using this criterion we show that it is possible to design experimental conditions that improve reaction yields.

This is to our knowledge the first report of a photochemical derivatization using organothiols. Our experiments show that it is possible to take advantage of the electronic properties of graphitic materials in order to photocatalyse reactions in solution. In particular, desulfurization reactions such as the one observed in our experiments are important applications in the synthesis of bioactive compounds (e.g. carbohydrates, peptides) and in fuel cleanup. In principle this type of reactions could be of general application to nanotube, graphite nanosheets and graphene modification, but also expand the uses of these carbon nanomaterials in the area of organic catalysis.

Acknowledgements. This publication has emanated from research conducted with the financial support of Science Foundation Ireland under Grant Number 09/RFP/CAP2174 and of the Irish Council for Science Engineering and Technology (IRCSET) under the Postdoctoral Fellowship Scheme. The 
authors are grateful to Dr. Cormac McGuinness and Dr. Michael E.G. Lyons for granting access to XPS and electrochemical instrumentation respectively, and to Dr. Manuel Ruether for technical support.

Supporting Information Available. Supplementary XPS, CV and IRRAS data are reported. This material is available free of charge via the Internet at http://pubs.acs.org. 


\section{References}

1. Allen, M. J.; Tung, V. C.; Kaner, R. B. Chem. Rev. 2010, 110, 132-145.

2. Loh, K. P.; Bao, Q. L.; Ang, P. K.; Yang, J. X. J. Mater. Chem. 2010, 20, 2277-2289.

3. Lee, B.; Chen, Y.; Duerr, F.; Mastrogiovanni, D.; Garfunkel, E.; Andrei, E. Y.; Podzorov, V. Nano Lett. 2010, 10, 2427-2432.

4. Liu, L. H.; Lerner, M. M.; Yan, M. D. Nano Lett. 2010, 10, 3754-3756.

5. Chakraborty, S.; Guo, W. H.; Hauge, R. H.; Billups, W. E. Chem. Mater. 2008, 20, 3134-3136.

6. Colavita, P. E.; Sun, B.; Tse, K.-Y.; Hamers, R. J. J. Am. Chem. Soc. 2007, 129, 13554-13565.

7. Nichols, B. M.; Butler, J. E.; Russell, J. N.; Hamers, R. J. J. Phys. Chem. B 2005, 109, 20938-20947.

8. Yu, S. S. C.; Downard, A. J. Langmuir 2007, 23, 4662-4668.

9. Bergeld, J.; Kasemo, B.; Chakarov, D. Phys. Chem. Chem. Phys. 2008, 10, 1151-1155.

10. Chakarov, D. V.; Gleeson, M. A.; Kasemo, B. J. Chem. Phys. 2001, 115, 9477-9483.

11. Modestov, A. D.; Gun, J.; Lev, O. J. Electroanal. Chem. 1999, 476, 118-131.

12. Modestov, A. D.; Gun, J.; Lev, O. J. Electroanal. Chem. 2000, 491, 39-47.

13. Modestov, A. D.; Gun, J.; Lev, O. Langmuir 2000, 16, 4678-4687.

14. Liu, H. T.; Ryu, S. M.; Chen, Z. Y.; Steigerwald, M. L.; Nuckolls, C.; Brus, L. E. J. Am. Chem. Soc. 2009, 131, 17099-17101.

15. Zhou, Y. K.; Holme, T.; Berry, J.; Ohno, T. R.; Ginley, D.; O'Hayre, R. J. Phys. Chem. C 2010, $114,506-515$.

16. Zhou, Y. K.; Pasquarelli, R.; Holme, T.; Berry, J.; Ginley, D.; O'Hayre, R. J. Mater. Chem. 2009, $19,7830-7838$.

17. Carrillo, A.; Swartz, J. A.; Gamba, J. M.; Kane, R. S.; Chakrapani, N.; Wei, B. Q.; Ajayan, P. M. Nano Lett. 2003, 3, 1437-1440.

18. Neises, B.; Steglich, W. Angew. Chem., Int. Ed. Engl. 1978, 7, 522-524.

19. Cha, S.-H.; Kim, K.-H.; Kim, J., -U.; Lee, W., -K.; Lee, J. C. J. Phys. Chem. C 2008, 112, 1386213868.

20. Leitner, T.; Kattner, J.; Hoffmann, H. Appl. Spectrosc. 2003, 57, 1502-1509.

21. Proctor, A.; Sherwood, P. M. A. Anal. Chem. 1982, 54, 13-19.

22. Shirley, D. A. Phys. Rev. B 1972, 5, 4709-4714. 
23. Kissinger, P. T.; Heineman, W. R., Laboratory Techniques In Electroanalytical Chemistry. 2nd ed.; Marcel Dekker: New York, 1996.

24. Nuzzo, R. G.; Allara, D. L. J. Am. Chem. Soc. 1983, 105, 4481-4483.

25. Porter, M. D.; Bright, T. B.; Allara, D. L.; Chidsey, C. E. D. J. Am. Chem. Soc. 1987, 109, 35593567.

26. Nuzzo, R. G.; Zegarski, B. R.; Dubois, L. H. J. Am. Chem. Soc. 1987, 109, 733-740.

27. Nuzzo, R. G.; Dubois, L. H.; Allara, D. L. J. Am. Chem. Soc. 1990, 112, 558-569.

28. Tolstoy, V. P.; Chernyshova, I.; Skryshevsky, V. A., Handbook of Infrared Spectroscopy of Ultrathin Films. John Wiley \& Sons: Hoboken, NJ, 2003.

29. Bieri, M.; Burgi, B. J. Phys. Chem. B 2005, 109, 22476-22485.

30. Arnold, R.; Azzam, W.; Terfort, A.; Woll, C. Langmuir 2002, 18, 3980-3992.

31. Saavedra, H. M.; Thompson, C. M.; Hohman, J. N.; Crespi, V. H.; Weiss, P. S. J. Am. Chem. Soc. 2009, 131, 2252-2259.

32. Cyr, D. M.; Venkataraman, B.; Flynn, G. W.; Black, A.; Whitesides, G. M. J. Phys. Chem. 1996, $100,13747-13759$.

33. Kneten, K. R.; McCreery, R. L. Anal. Chem. 1992, 64, 2518-2524.

34. Rice, R. J.; McCreery, R. L. Anal. Chem. 1989, 61, 1637-1641.

35. McDermott, M. T.; Kneten, K.; McCreery, R. L. J. Phys. Chem. 1992, 96, 3124-3130.

36. Davis, T. J.; Moore, R. R.; Banks, C. E.; Compton, R. G. J. Electroanal. Chem. 2004, 574, $123-$ 152.

37. Finklea, H. O., Electrochemistry of organized monolayers of thiols and related molecules on electrodes. In Electroanalytical Chemistry: A Series of Advances, Vol 19, 1996; Vol. 19, pp 109-335.

38. Guo, L. H.; Facci, J. S.; McLendon, G.; Mosher, R. Langmuir 1994, 10, 4588-4593.

39. Miller, C.; Cuendet, P.; Gratzel, M. J. Phys. Chem. 1991, 95, 877-886.

40. Poirier, D. M.; Weaver, J. H.; Kikuchi, K.; Achiba, Y. Z. Phys. D: At., Mol. Clusters 1993, 26, 7983.

41. Sette, F.; Wertheim, G. K.; Ma, Y.; Meigs, G.; Modesti, S.; Chen, C. T. Phys. Rev. B: Condens. Matter Mater. Phys. 1990, 41, 9766-9770.

42. van Attekum, P. M. T. M.; Wertheim, G. K. Phys. Rev. Lett. 1979, 43, 1896-1898.

43. Powell, C. J.; Jablonski, A., NIST Electron Inelastic-Mean-Free-Path Database, Version 1.1. In National Institute of Standards and Technology, Gaithersburg, MD: 2000.

44. Azzam, W.; Wehner, B. I.; Fischer, R. A.; Terfort, A.; Woll, C. Langmuir 2002, 18, 7766-7769. 
45. Kohli, P.; Taylor, K. K.; Harris, J. J.; Blanchard, G. J. J. Am. Chem. Soc. 1998, 120, 11962-11968.

46. Jager, B.; Schurmann, H.; Muller, H. U.; Himmel, H. J.; Neumann, M.; Grunze, M.; Woll, C. Phys. Chem. Chem. Phys. 1997, 202, 263-272.

47. Hammond, G. S.; Sen, J. N.; Boozer, C. E. J. Am. Chem. Soc. 1955, 77, 3244-3248.

48. Thomassin, J.-M.; Kollar, J.; Caldarella, G.; Germain, A.; Jerome, R.; Detrembleur, C. J. Membr. Sci. 2007, 303, 525-527.

49. Dondoni, A. Angew. Chem., Int. Ed. 2008, 47, 8995-8997.

50. Griesbaum, K. Angew. Chem., Int. Ed. 1970, 9, 273-287.

51. Lockett, M. R.; Smith, L. M. J. Phys. Chem. C 2010, 114, 12635-12641.

52. Izutsu, K., Properties of solvents and solvent classification. In Electrochemistry in Nonaqueous Solutions, Wiley VCH: Weinheim, 2009; pp 3-26.

53. Lockett, M. R.; Carlisle, J. C.; Le, D. V.; Smith, L. M. Langmuir 2009, 25, 5120-5126.

54. Alam, M. M.; Sato, M.; Watanabe, A.; Akasaka, T.; Ito, O. J. Phys. Chem. A 1998, 102, 7447-7451.

55. Sheraton, D. F.; Murray, F. E. Can. J. Chem. 1981, 59, 2750-2754.

56. Vaghjiani, G. L. J. Chem. Phys. 1993, 99, 5936-5943.

57. Greenaway, D. L.; Harbeke, G.; Bassani, F.; Tosatti, E. Phys. Rev. 1969, 178, 1340-1348.

58. Johnson, L. G.; Dresselhaus, G. Phys. Rev. B 1973, 7, 2275.

59. Eklund, P. C.; Smith, D. S.; Murthy, V. R. K. Synth. Met. 1981, 3, 111-122.

60. Colavita, P. E.; Streifer, J. A.; Sun, B.; Wang, X.; Warf, P.; Hamers, R. J. J. Phys. Chem. C 2008, $112,5102-5112$.

61. Lockett, M. R.; Smith, L. M. Langmuir 2010, 26, 16642-16646.

62. Pleskov, Y. V.; Gurevich, Y. Y., Semiconductor photoelectrochemistry. Consultants Bureau: New York, 1986.

63. Borjas Severeyn, R.; Gale, R. J., Photoemission phenomena at metallic and semiconductor electrodes. In Spectroelectrochemistry: Theory and practice, Gale, R. J., Ed. Plenum Press: New York, 1988; pp 41-86.

64. Buxton, G. V.; Greenstock, C. L.; Helman, W. P.; Ross, A. B. J. Phys. Chem. Ref. Data 1988, 17, 513-886.

65. Schwarz, H. A. J. Chem. Educ. 1981, 58, 101-105.

66. Afanasev, V. V., Internal photoemission spectroscopy: principles and applications. Elsevier: Oxford, UK, 2008.

67. Maran, F.; Celadon, D.; Severin, M. G.; Vianello, V. J. Am. Chem. Soc. 1991, 113, 9320-9329. 
68. Peter, F. A.; Neta, P. J. Phys. Chem. 1972, 76, 630-635.

69. Pelc, A.; Sailer, W.; Scheier, P.; Mark, T. D.; Illenberger, E. Chem. Phys. Lett. 2004, 392, 465-469.

70. Ayscough, P. B.; Mach, K.; Oversby, J. P.; Roy, A. K. J. Chem. Soc., Faraday Trans. 1971, 67, 360-374.

71. Ayscough, P. B.; Oversby, J. P. J. Chem. Soc., Faraday Trans. 1971, 67, 1365-1375.

72. Koppe, R.; Kasai, P. H. Chem. Phys. 1994, 189, 401-413.

73. Stubbe, J.; van der Donk, W. A. Chem. Rev. 1998, 98, 705-762.

74. Bump, E. A.; Brown, J. M. Pharmacol. Ther. 1990, 47, 117-136.

75. Kooymans, E. C. Pure Appl. Chem. 1967, 15, 81-88.

76. Lal, M.; Armstrong, D. A. Can. J. Chem.-Rev. Can. Chim. 1985, 63, 30-32.

77. Tung, T. L.; Kuntz, R. R. Radiat. Res. 1973, 55, 256-264.

78. Pryor, W. A.; Olsen, E. G. J. Am. Chem. Soc. 1978, 100, 2852-2856.

79. Tung, T. L.; Kuntz, R. R. Radiat. Res. 1973, 55, 10-17.

80. Safarik, I.; Strausz, O. P. Rev. Chem. Intermed. 1985, 6, 143-173.

81. Peng, H. P.; Reverdy, P.; Khabashesku, V. N.; Margrave, J. L. Chem. Commun. (Cambridge, U. K.) 2003, 362-363.

82. Peng, H. Q.; Alemany, L. B.; Margrave, J. L.; Khabashesku, V. N. J. Am. Chem. Soc. 2003, 125, 15174-15182.

83. Hamilton, C. E.; Lomeda, J. R.; Sun, Z.; Tour, J. M.; Barron, A. R. Nano Research 2010, 3, 138145 .

84. Ying, Y.; Saini, R. K.; Liang, F.; Sadana, A. K.; Billups, W. E. Org. Lett. 2003, 5, 1471-1473.

85. Chattopadhyay, J.; Chakraborty, S.; Mukherjee, A.; Wang, R.; Engel, P. S.; Billups, W. E. J. Phys. Chem. C 2007, 111, 17928-17932.

86. Bard, A. J. Pure Appl. Chem. 1971, 25, 379-393.

87. Faulkner, L. R.; Bard, A. J. J. Am. Chem. Soc. 1968, 90, 6284-6290.

88. Ayscough, P. B.; Oversby, J. P. J. Chem. Soc., Faraday Trans. 1972, 68, 1153-1163.

89. Adams, G. E.; McNaught.Gs; Michael, B. D. J. Chem. Soc., Faraday Trans. 1968, 64, 902-910.

90. Reid, D. L.; Shustov, G. V.; Armstrong, D. A.; Rauk, A.; Schuchmann, M. N.; Akhlaq, M. S.; von Sonntag, C. Phys. Chem. Chem. Phys. 2002, 4, 2965-2974.

91. Fawcett, W. R. J. Phys. Chem. 1993, 97, 9540-9546. 
92. Tremaine, P. R.; Dixon, R. S. J. Phys. Chem. 1978, 82, 224-226.

93. Wagner, E.; Kalinowski, M. K. Monatsh. Chem. 1984, 115, 1313-1317.

94. Rossky, P. J.; Schnitker, J. J. Phys. Chem. 1988, 92, 4277-4285.

95. Gavlas, J. F.; Jou, F. Y.; Dorfman, L. M. J. Phys. Chem. 1974, 78, 2631-2635.

96. Xia, C. G.; Peon, J.; Kohler, B. J. Chem. Phys. 2002, 117, 8855-8866.

97. Shkrob, I. A.; Sauer, M. C. J. Phys. Chem. A 2002, 106, 9120-9131.

98. Leu, A. D.; Jha, K. N.; Freeman, G. R. Can. J. Chem.-Rev. Can. Chim. 1982, 60, 2342-2350.

99. Tsierkezos, N. G. J. Solution Chem. 2007, 36, 1301-1310.

100. Hoon, M.; Fawcett, W. R. J. Phys. Chem. A 1997, 101, 3726-3730. 


\section{FIGURE CAPTIONS}

Figure 1. IRRAS spectra of organic layers obtained after photochemical grafting for 15 min on HOPG using DMF organothiol solutions with water. Spectra were baseline corrected and offset for clarity.

Figure 2. Cyclic voltammograms of bare (trace A) and modified HOPG samples after photochemical reaction with MUA (trace B), after exposure to MUA solution without irradiation (trace C) and after photochemical reaction with EMU (trace D) in $0.001 \mathrm{M} \mathrm{K}_{3} \mathrm{Fe}(\mathrm{CN})_{6}$ and $0.1 \mathrm{M} \mathrm{KCl}$, vs $\mathrm{Ag} / \mathrm{AgCl}$ at $0.075 \mathrm{~V} / \mathrm{s}$.

Figure 3. XPS spectra of the C1s region of HOPG after cleavage (trace A), after irradiation in DMF for 15 min (trace B) and after photochemical reaction with MUA (trace C).

Figure 4. Cyclic voltammograms of bare (trace A) and modified HOPG after photochemical reaction with UA (trace B) in $0.001 \mathrm{M} \mathrm{K}_{3} \mathrm{Fe}(\mathrm{CN})_{6}$ and $0.1 \mathrm{M} \mathrm{KCl}$, vs $\mathrm{Ag} / \mathrm{AgCl}$ at $0.075 \mathrm{~V} / \mathrm{s}$. The inset shows the IRRAS spectrum of organic layers obtained on HOPG surfaces after reaction with UA (trace B) and, for comparison purpose, after cleavage (trace A). All spectra were obtained using a freshly cleaved HOPG surface as background; spectra were baseline corrected and offset for clarity.

Figure 5. (a) Representative IRRAS spectra in the $\mathrm{C}=\mathrm{O}$ stretching region of HOPG samples after photochemical reaction with MUA in dry DMF (trace A), HPLC grade DMF (trace B) and after $\mathrm{H}_{2} \mathrm{O}$ addition to a concentration of $5 \mathrm{mM}$ (trace C), under 15 min of irradiation; (b) after reaction in $\mathrm{H}_{2} \mathrm{O}$ : MUA 1:1 solution under $15 \mathrm{~min}$ (trace A) and $3 \mathrm{~h}$ of irradiation (trace B). Spectra were baseline corrected and offset for clarity.

Figure 6. IRRAS spectrum of organic layer on HOPG samples after photochemical reaction with MUA solution using water (trace A) and using a thermally activated radical initiator (ACVA) at $75^{\circ} \mathrm{C}$ (trace B). Spectra were baseline corrected and offset for clarity. 
Figure 7. Cyclic voltammograms of HOPG electrodes after photochemical reaction with EMU and water (both $5 \mathrm{mM}$ ) in solution using DMF (trace B), EtOH (trace C) and $\mathrm{CH}_{3} \mathrm{CN}$ (trace D) as solvents; the $\mathrm{CV}$ for freshly cleaved HOPG (trace A) is also reported for comparison purposes. Voltammograms are recorded in $0.001 \mathrm{M} \mathrm{K}_{3} \mathrm{Fe}(\mathrm{CN})_{6}$ and $0.1 \mathrm{M} \mathrm{KCl}$, vs $\mathrm{Ag} / \mathrm{AgCl}$ at $0.075 \mathrm{~V} / \mathrm{s}$.

Figure 8. Proposed mechanism for organothiol grafting on HOPG: photoemission of electrons from HOPG into the liquid is facilitated via either proton or solvent traps. These two possible pathways both result in the generation of alkyl radicals in proximity of the carbon surface. 


\section{Scheme 1.}
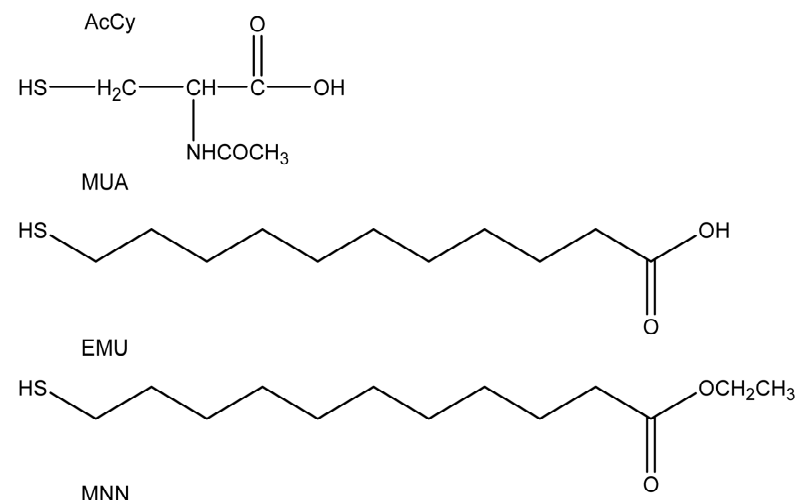

HS 
Figure 1. IRRAS spectra of organic layers obtained after photochemical grafting for 15 min on HOPG using DMF organothiol solutions with water. Spectra were baseline corrected and offset for clarity.

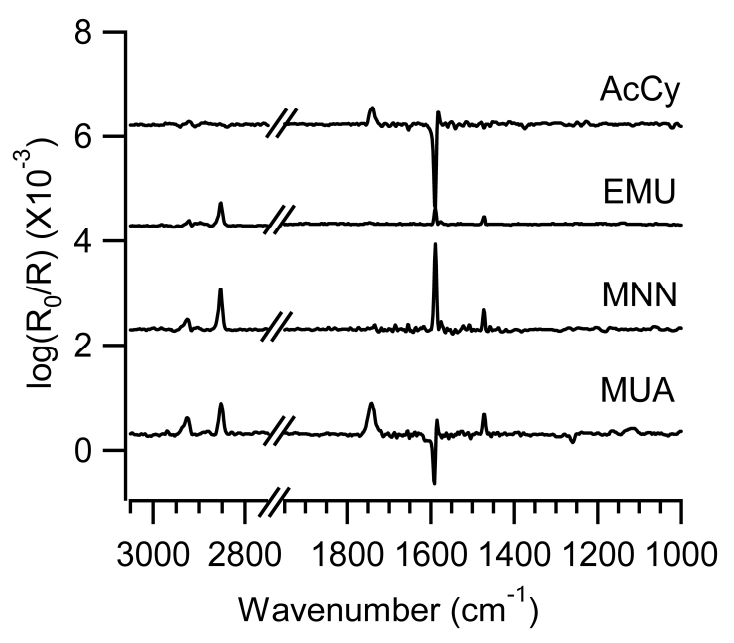


Figure 2. Cyclic voltammograms of bare (trace A) and modified HOPG samples after photochemical reaction with MUA (trace B), after exposure to MUA solution without irradiation (trace C) and after photochemical reaction with EMU (trace D) in $0.001 \mathrm{M} \mathrm{K}_{3} \mathrm{Fe}(\mathrm{CN})_{6}$ and $0.1 \mathrm{M} \mathrm{KCl}$, vs $\mathrm{Ag} / \mathrm{AgCl}$ at $0.075 \mathrm{~V} / \mathrm{s}$.

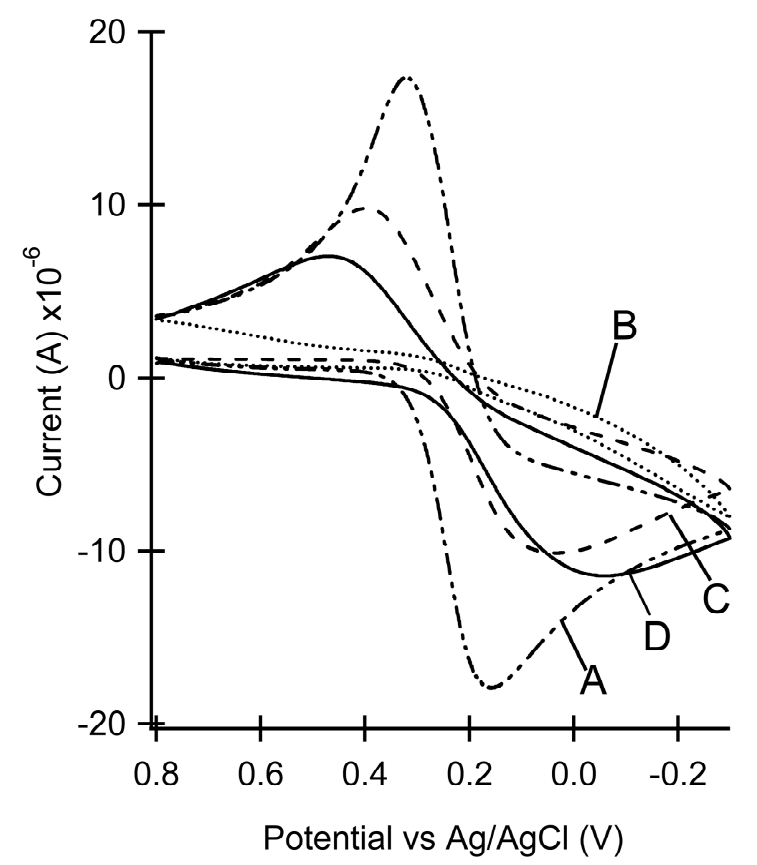


Figure 3. XPS spectra of the C1s region of HOPG after cleavage (trace A), after irradiation in DMF for 15 min (trace B) and after photochemical reaction with MUA (trace C).

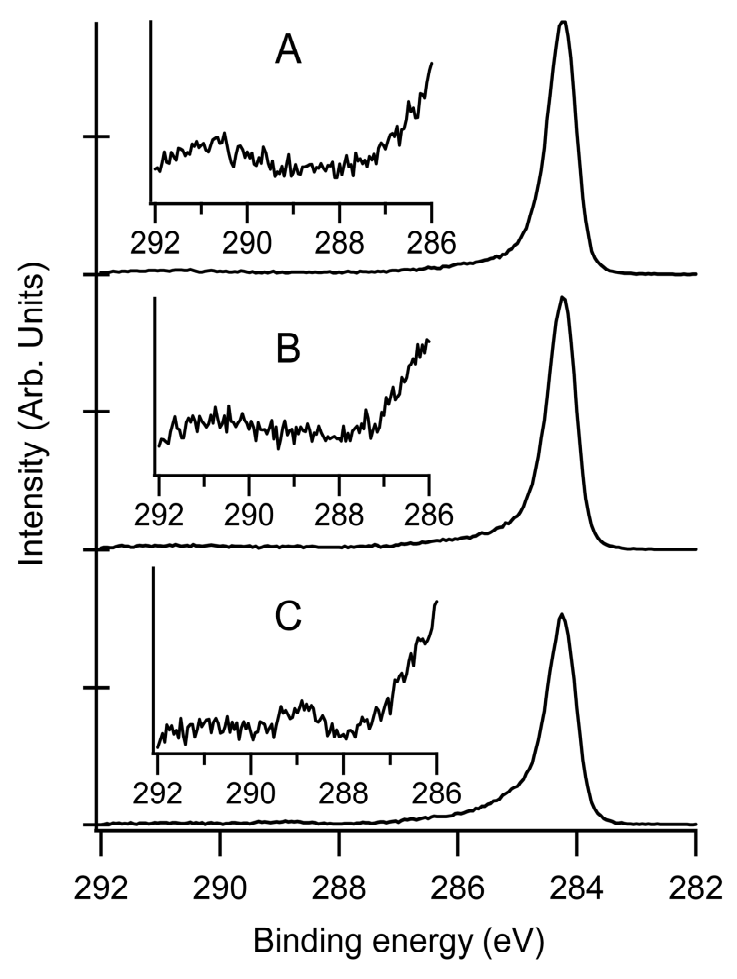


Figure 4. Cyclic voltammograms of bare (trace A) and modified HOPG after photochemical reaction with UA (trace B) in $0.001 \mathrm{M} \mathrm{K}_{3} \mathrm{Fe}(\mathrm{CN})_{6}$ and $0.1 \mathrm{M} \mathrm{KCl}$, vs $\mathrm{Ag} / \mathrm{AgCl}$ at $0.075 \mathrm{~V} / \mathrm{s}$. The inset shows the IRRAS spectrum of organic layers obtained on HOPG surfaces after reaction with UA (trace B) and, for comparison purpose, after cleavage (trace A). All spectra were obtained using a freshly cleaved HOPG surface as background; spectra were baseline corrected and offset for clarity.

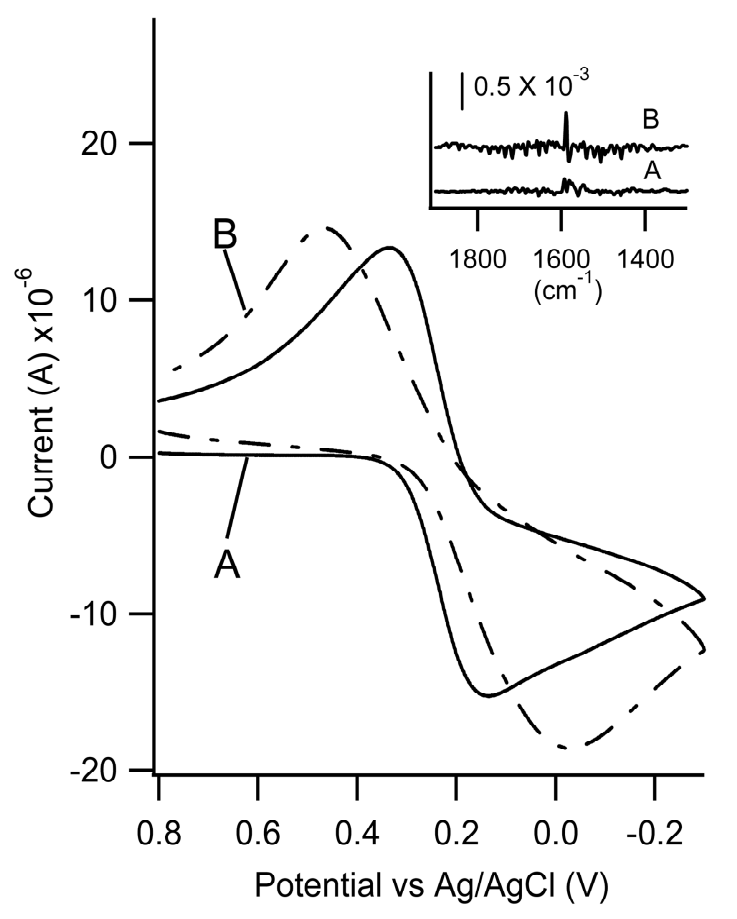


Figure 5. (a) Representative IRRAS spectra in the $\mathrm{C}=\mathrm{O}$ stretching region of HOPG samples after photochemical reaction with MUA in dry DMF (trace A), HPLC grade DMF (trace B) and after $\mathrm{H}_{2} \mathrm{O}$ addition to a concentration of $5 \mathrm{mM}$ (trace C), under 15 min of irradiation; (b) after reaction in $\mathrm{H}_{2} \mathrm{O}$ : MUA 1:1 solution under $15 \mathrm{~min}$ (trace A) and $3 \mathrm{~h}$ of irradiation (trace B). Spectra were baseline corrected and offset for clarity.
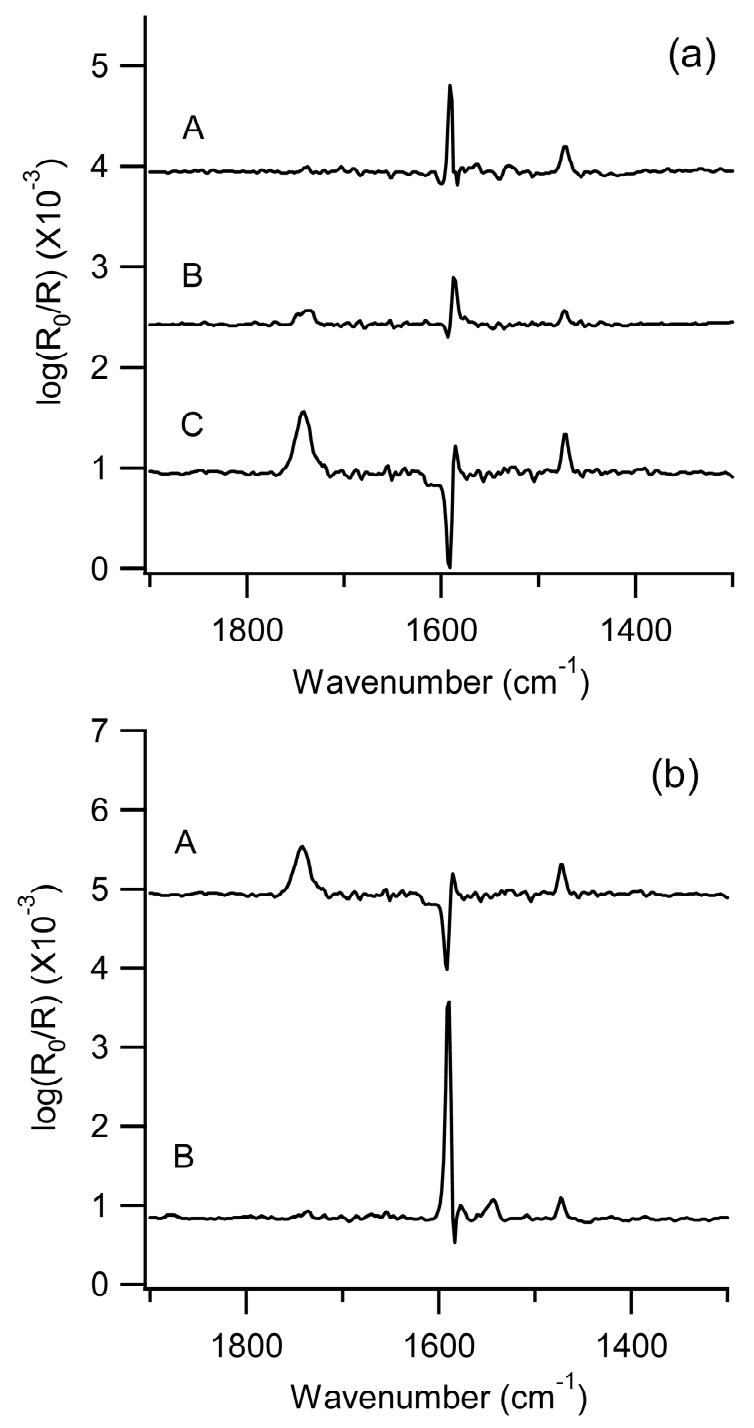
Figure 6. IRRAS spectrum of organic layer on HOPG samples after photochemical reaction with MUA solution using water (trace A) and using a thermally activated radical initiator (ACVA) at $75^{\circ} \mathrm{C}$ (trace B). Spectra were baseline corrected and offset for clarity.

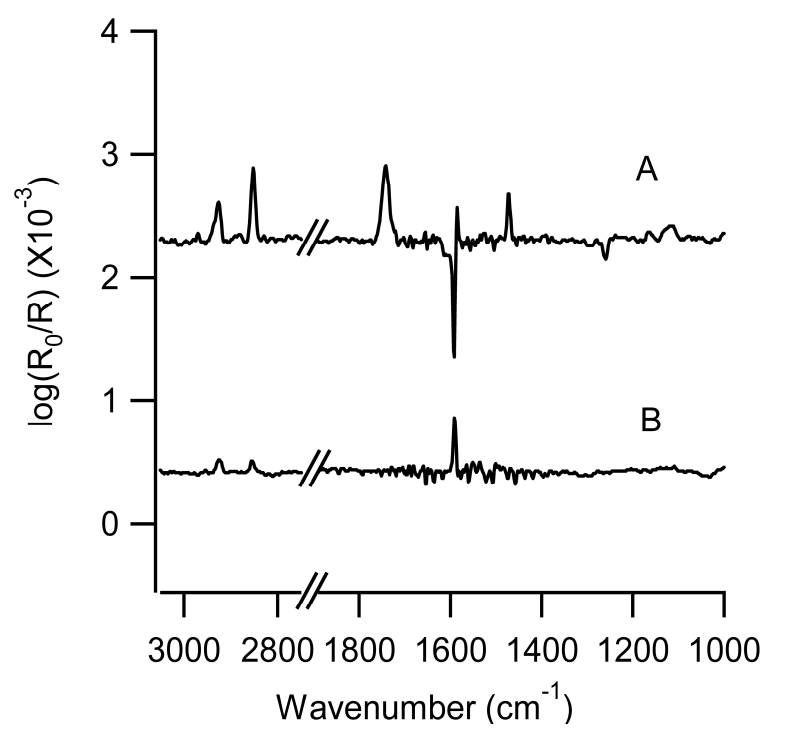


Figure 7. Cyclic voltammograms of HOPG electrodes after photochemical reaction with EMU and water (both $5 \mathrm{mM}$ ) in solution using DMF (trace B), $\mathrm{EtOH}$ (trace C) and $\mathrm{CH}_{3} \mathrm{CN}$ (trace D) as solvents; the $\mathrm{CV}$ for freshly cleaved HOPG (trace A) is also reported for comparison purposes. Voltammograms are recorded in $0.001 \mathrm{M} \mathrm{K}_{3} \mathrm{Fe}(\mathrm{CN})_{6}$ and $0.1 \mathrm{M} \mathrm{KCl}$, vs $\mathrm{Ag} / \mathrm{AgCl}$ at $0.075 \mathrm{~V} / \mathrm{s}$.

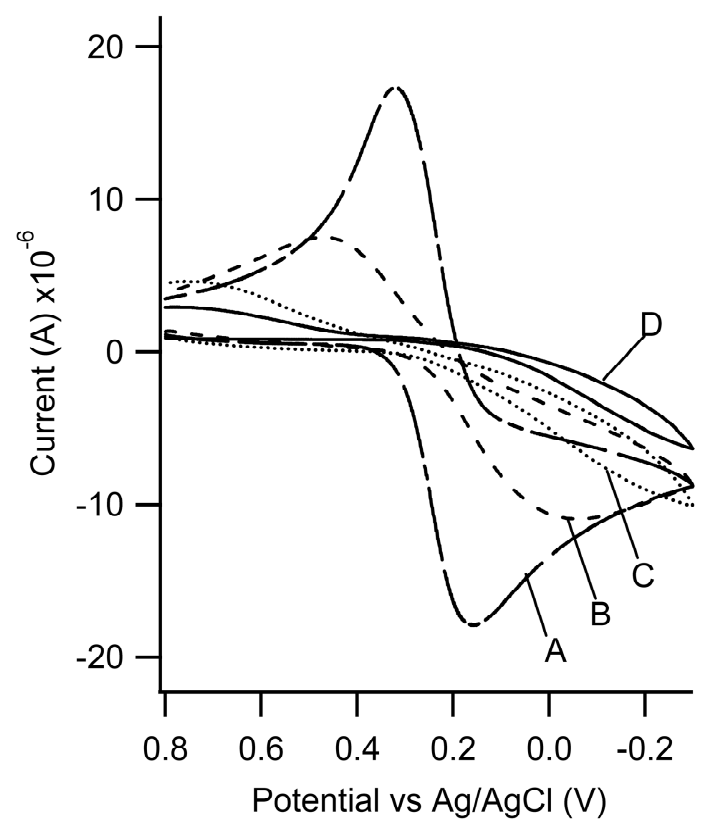


Figure 8. Proposed mechanism for organothiol grafting on HOPG: photoemission of electrons from HOPG into the liquid is facilitated via either proton or solvent traps. These two possible pathways both result in the generation of alkyl radicals in proximity of the carbon surface.

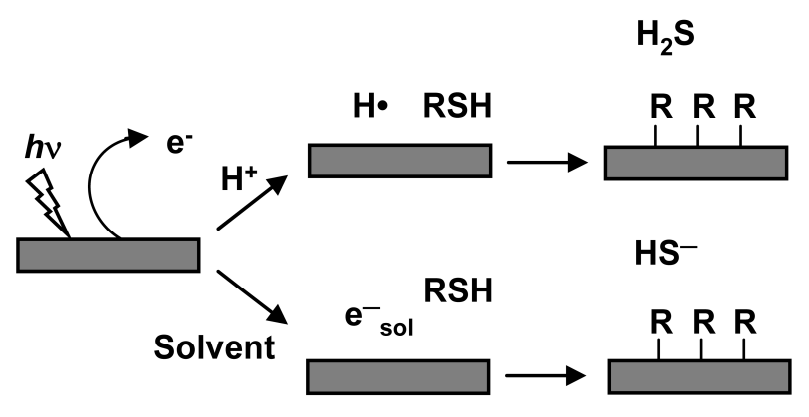


TOC Figure

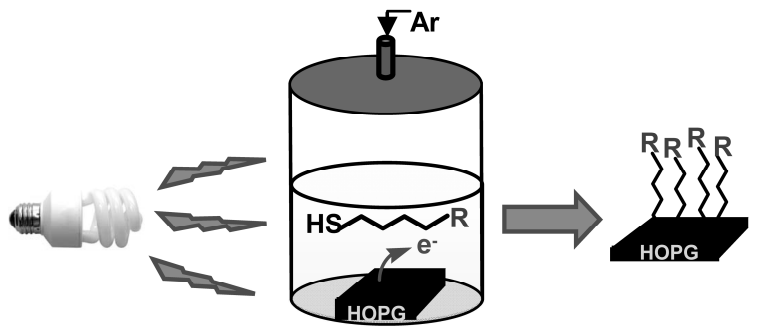

